5. Vardar R, Sweis $R$, Anggiansah A, Wong $\mathbf{T}$, Fox MR. Upper esophageal sphincter and esophageal motility in patients with chronic cough and reflux: assessment by high-resolution manometry. Dis Esophagus. 2013;26(3):219-225.

6. Wang $K$, Duan LP, Ge $Y$, Xia ZW, Xu ZJ. A comparative study of 22-channel water-perfusion system and solid-state system with 36-sensors in esophageal manometery. BMC Gastroenterol. 2012;12:157.
7. Passaretti S, Mazzoleni G, Vailati C, Testoni PA. Oropharyngeal acid reflux and motility abnormalities of the proximal esophagus. World J Gastroenterol. 2016;22(40):8991-8998.

8. Perry KA, Enestvedt CK, Lorenzo CS, et al. The integrity of esophagogastric junction anatomy in patients with isolated laryngopharyngeal reflux symptoms. J Gastrointest Surg. 2008;12(11):1880-1887.

9. Tomonaga T, Awad ZT, Filipi CJ, et al. Symptom predictability of reflux-induced respiratory disease. Dig Dis Sci. 2002;47(1):9-14.

\title{
ĐIỀU TRI BÊNH NHÂN NGộ ĐộC MộT SỐ MA TÚY TẠI TRUNG TÂM CHỐNG ĐộC BỆNH VIÊ̂N BACCH MAI
}

\section{TÓM TẮT}

Mục tiêu: Nhận xét các biên pháp điều trị bênh nhân ngộ độc cấp một số ma túy không phải nhóm opi tại Trung tâm Chống độc Bênh viên Bach Mai. Đối tươning và phương pháp: Nghiên cứu mồ tả 72 bệnh nhẩn ngô đôc cấp ma túy không phải nhóm opi điêuu trị tại Trung tâm Chống độc Bệnh viện Bạch Mai từ tháng 1/2017 đến 6/2019. Kết quả: Các loai ma túy gặp trong nghiên cứu là Amphetamin $(29,2 \%)$, MET $(22,2 \%)$, MDMA $(19,4 \%)$, THC $(20,8 \%)$, Ketamin $(8,3 \%)$. Các biện pháp điêuu trị chính là hối sức tích cực và điều trị hỗ trợ: hồi sức tuần hoàn, sử dung vân mạch $(1,4 \%)$, tăng cường bài niệu $(98,6 \%)$; hỗ trợ hô hẩp $25 \%$ (thở oxy $19,4 \%$, thở máy $5,6 \%$, nhiều nhất là nhóm ketamin); sử dụng an thần 43,1\% (nhiêu nhất ở nhóm amphetamin $61,9 \%$; dùng thuốc diazepam là 90,3\%). Kết quả điêuu trị: khỏi 91,7\%, còn rối loan tâm thân sau điều trị $8,3 \%$. Kết luân: Hiên tai chưa có thuốc kháng độc đắc hiệu nên điêu trị ngộ độc các loại ma túy không phải nhóm opi cần sự phối hợp của các biện pháp hôi sức tích cực, điều trị các triêu chứng và biến chứng.

Tư khóa: ngộ độc ma túy, điều trị.

\section{SUMMARY}

TREATMENT MEASURES FOR DRUGS OF ABUSE POISONING AT POISON CONTROL CENTER OF BACH MAI HOSPITAL

Objective: to evaluate treatment measures for patients with non-opium drugs of abuse poisoning at Poison Control Center, Bach Mai Hospital. Subjects and Methods: A observational study included 72 poisoned non-opium drugs poisoning patients treated at Poison Control Center Bach Mai Hospital from $1 / 2017$ to 6/2019. Results: The drugs found in the study were Amphetamine (29.2\%), MET (22.2\%),

${ }^{1}$ Trung Tâm Chông Độc Bệnh viện Bạch Mai

${ }^{2}$ Bênh viên Lão khoa Trung ương

Chịu trách nhiệm chính: Đặng Thị Xuân

Email: xuandangthi@bachmai.edu.vn

Ngày nhận bài: 25.2.2021

Ngày phản biên khoa hoc: 5.4.2021

Ngày duyệt bài: 13.4 .2021
Đặng Thị Xuân ${ }^{1}$, Nguyễn Trung Anh² MDMA (19.4\%), THC (20.8\%), Ketamine (8.3\%). The applied treatment measures for patients were resuscitation and supportive therapy: cardiovascular support, using vasopressors $(1,4 \%)$, increased diuresis (98.6\%); Respiratory support 25\% (oxygen $19.4 \%$; mechanical ventilation $5.6 \%$, the most in the ketamine group); Using sedation $43.1 \%$ (the most in the amphetamine group 61.9\%; using diazepam was $90.3 \%)$. The outcome: recovery $(91.7 \%)$, mental disorder $8.3 \%$. Conclusion: There was no specific antidote, so the treatment required for poisoning of non-opium drugs was a combination of aggressive resuscitation measures and symptomatic treatment.

Key words: drugs of abuse poisoning, treatment

\section{I. ĐĂT VẤN ĐỀ}

Ma túy là một vấn nạn của nhiều nước trên thế giới cũng như của nước ta. Tại Việt Nam, heroin là ma túy nhóm opi được sử dung nhiều nhất trong những năm trước đây, chiểm $3 / 4$ số loại chất gây nghiên thường được sử dụng, còn lại là cần sa, ma túy tổng hợp [1]. Thời gian gần đây, việc sử dụng các loại ma túy tổng hợp amphetamin và các dẫn chẩt (kẹo, thuốc lắc, ma túy đá...), ketamin, cần sa, lá khát, nấm, bóng cười... ngày càng gia tăng, đặc biệt trong nhóm người trẻ tuổi.

Các loại ma túy không phải opi rất đa dạng, độc tính phức tạp. Ma túy tổng hợp được tổng hợp từ một hoặc nhiều loại tiền chất, hoặc pha trộn với tî̉ lê khác nhau cho ra các loại ma túy khác nhau. Cỏ Mỹ có thể được pha tẩm thêm ma túy tổng hợp... Các ma túy mới xuất hiện nhiều hơn, tình trạng lạm dụng tăng lên, gây khó khăn trong kiểm soát, chẩn đoán và điêu trị. Các loại ma túy mới có độc tính mạnh, phức tạp, không chỉ gây hại cho bản thân bệnh nhân mà còn gây nguy hiểm cho người xung quanh do loạn thân, ảo giác, có trường hợp nhập viện do tổn thương tim, suy tim, loan nhịp tim, hôn mê, suy đa tạng, một số trường hợp tử vong. 
Tại Trung tâm Chống độc Bệnh viện Bạch Mai trước đây chủ yếu là cấp cứu các bệnh nhân quá liều heroin, gần đây số bệnh nhân ngộ độc ma túy tổng hợp, cần sa...ngày càng tăng, vì vậy việc cấp cứu và điều trị cũng phức tạp hơn. Hiện tại còn thiếu các đánh giá tổng quát các biện pháp điều trị các ma túy mới, vì vậy chúng tôi tiến hành nghiên cứu đề tài với mục tiêu "Nhận xét các biện pháp điều trị bệnh nhân ngộ độc cấp một số ma túy không phải nhóm opi tại Trung tâm Chống độc Bệnh viện Bạch Mai".

\section{II. ĐỐI TƯỢNG VÀ PHƯƠNG PHÁP NGHIÊN CỨU}

2.1. Đối tượng nghiên cứu: Bệnh nhân ngộ độc cấp ma túy không phải nhóm opi vào điều trị tại Trung tâm Chông độc từ 1/2017 đến $6 / 2019$

* Tiêu chuẩn chọn bệnh nhân: Bệnh nhân có các tiêu chuẩn sau [2]

- Bệnh sử sử dụng ma túy (ma túy đá, thuốc lắc, ketamin, cần sa, ...)

- Biểu hiện lâm sàng ngộ độc ma túy

- Xét nghiệm độc chất nước tiểu thấy ma túy.

* Tiêu chuẩn loại trừ:

- Bệnh nhân sử dụng đồng thời ma túy nhóm opi (heroin, morphin, methadon)

- Ngộ độc đồng thời các chất khác: thuốc, hóa chất bảo vệ thực vật...

\subsection{Phương pháp nghiên cứu}

- Thiết kế nghiên cứu: Nghiên cứu mô tả

- Cõ̃ mẫu: cỡ mẫu thuận tiện, chọn tất cả bệnh nhân đủ tiêu chuẩn trong thời gian nghiên cứu.

- Tiến hành nghiên cứu: thu thập số liệu theo mẫu bệnh án nghiên cứu thống nhất

- Đặc điểm chung: tuổi, giới, nghề nghiệp, tiền sử nghiện ma túy.

- Loại ma túy sử dụng, hoàn cảnh, nơi và cách sử dụng.

- Xét nghiệm định tính các loại ma túy trong nước tiểu tại viện Giám định pháp $Y$ bằng phương pháp sắc kí khí (GS). Sữ dụng máy ủ mẫu GC6890N và máy phân tích mẫu ATG1888.
- Các biện pháp điều trị:

+ Hồi sức hô hấp: bóp bóng, nội khí quản, thở máy

+ Hồi sức tim mạch: truyền dịch,vận mạch, can thiệp mạch vành...

+ Điều trị triệu chứng (tâm thần kinh):

- Kích thích hưng cảm: bằng an thần

- Loạn thần, hoang tưởng, ảo giác: aminazin hoặc haloperidol

- Kết quả điêu trị:

+ Kết quả chung: khỏi, di chứng, tử vong

+ Di chứng:

- Tâm thần

- Tim mạch: suy tim, loạn nhịp tim

- Hô hấp: giãn phế quản, bệnh phổi mạn

2.3. Xử lý số liệu. Số liệu được xử lý theo phương pháp thống kê y học, sử dụng phần mềm SPSS 20.0. So sánh giá trị 2 trung bình bằng Student test, so sánh các tỉ lệ bằng $X^{2}$, mức ý nghĩa thống kê 95\%.

\section{KẾT QUẢ NGHIÊN CỨU}

\subsection{Một số đặc điểm chung}

Trong thời gian nghiên cứu, có 72 bệnh nhân đủ tiêu chuẩn chọn. Kết quả cho thấy:

- Tuổi trung bình: 30,57 \pm 9,3 tuổi. Giới: nam $72,2 \%$, Nữ $27,8 \%$

- Loại ma túy bệnh nhân sử dụng: Amphetamin: 21 BN (29,2\%); Metamphetamin (MET): $\quad 16$ BN (22,2\%); Methylenedioxy methamphetamine (MDMA) 14 BN $(19,4 \%)$; Ketamin: 6 BN 6 (8,3\%); Tetrahydrocannabinol (THC) 15 BN (20,8\%)

- Đường dùng: Đường uống (chiếm 79,2\%), đường chích hoặc hít (29,8\%).

\subsection{Các biệ̂n pháp điêu trị}

Các biện pháp điều trị được áp dụng cho ngộ độc ma túy không phải nhóm opi là hồi sức, điêu trị hỗ trợ các rối loạn về hô hấp, tuần hoàn, điều trị biến chứng. Các loại ma túy mới hiện nay chưa có thuốc giải độc đặc hiệu. Một số biện pháp điều trị được áp dụng như sau:

Bảng 1. Hỗ trợ tuần hoàn và truyền dịch

\begin{tabular}{|c|c|c|c|c|c|c|}
\hline \multirow{2}{*}{\multicolumn{2}{|c|}{$\begin{array}{c}\text { Đî̀u trị } \\
\text { Loại ma túy }\end{array}$}} & \multicolumn{2}{|c|}{ Truyền dich } & \multicolumn{2}{|c|}{ Vân mach } & \multirow[b]{2}{*}{$\mathbf{p}$} \\
\hline & & $\mathbf{n}$ & $\%$ & $\mathbf{n}$ & $\%$ & \\
\hline Amphetamin & $(n=21)$ & 21 & 100,0 & 0 & 0 & \multirow{6}{*}{0,47} \\
\hline MET & $(n=16)$ & 15 & 93,8 & 1 & 6,3 & \\
\hline MDMA $(n=$ & 14) & 14 & 100,0 & 0 & 0 & \\
\hline THC & $(n=15)$ & 15 & 100,0 & 0 & 0 & \\
\hline Ketamin & $(n=6)$ & 6 & 100,0 & 0 & 0 & \\
\hline Tổng & $(n=72)$ & 71 & 98,6 & 1 & 1,4 & \\
\hline
\end{tabular}

Nhân xét:

- Hẩu hết các bệnh nhân được truyền dịch tăng cường thải độc $(98,6 \%)$.

- Chỉ có 1 bệnh nhân ngộ độc MET phải dùng thuốc vận mạch $(1,4 \%)$. 
Bảng 2. Hỗ trợ hô hấp

\begin{tabular}{|c|c|c|c|c|c|c|c|}
\hline \multirow{2}{*}{ Loại ma túy Điều trị } & \multicolumn{2}{|c|}{ Số bệnh nhân } & \multicolumn{2}{|c|}{ Thở oxy } & \multicolumn{2}{|c|}{ Thở máy } & \multirow{2}{*}{ p } \\
\hline & $\mathbf{n}$ & $\%$ & $\mathbf{n}$ & $\%$ & $\mathrm{n}$ & $\%$ & \\
\hline Amphetamin $(n=21)$ & 17 & 81,0 & 3 & 14,3 & 1 & 4,8 & \\
\hline $\operatorname{MET}(n=16)$ & 12 & 75,0 & 2 & 12,5 & 2 & 12,5 & \\
\hline MDMA $(n=14)$ & 10 & 71,4 & 4 & 28,6 & 0 & 0 & $>0,05$ \\
\hline THC $(n=15)$ & 13 & 86,7 & 2 & 13,3 & 0 & 0 & $>0,05$ \\
\hline Ketamin $(n=6)$ & 2 & 33,3 & 3 & 50,0 & 1 & 16,7 & \\
\hline Tổng $(n=72)$ & 54 & 75,0 & 14 & 19,4 & 4 & 5,6 & \\
\hline
\end{tabular}

Nhận xét: Có 18 BN (25\%) cần hỗ trợ về hô hấp, trong đó có $14 / 72$ BN $(19,4 \%)$ ở tất cả các loại ma túy cần hỗ trợ hô hấp bằng thở oxy, tỉ lệ cao nhất là ở bệnh nhân ngộ độc ketamin và thấp nhẩt là ngộ độc MET (12,5\%). Có 4/72 BN $(5,6 \%)$ phải thở máy, tỉ lệ cao nhất trong nhóm dùng ketamin $(16,7 \%)$, không găp ở bênh nhân dùng THC, MDMA.

\section{Bảng 3. Sử dưng thuốc an thần}

\begin{tabular}{|c|c|c|c|c|c|}
\hline \multirow{2}{*}{ Loại ma túy } & \multicolumn{2}{|c|}{ Có } & \multicolumn{2}{|c|}{ Không } & \multirow{2}{*}{$\mathbf{P}$} \\
\hline & n & $\%$ & $\mathbf{n}$ & $\%$ & \\
\hline Amphetamin & 13 & 61,9 & 8 & 38,1 & \\
\hline$(n=16)$ & 5 & 31,3 & 11 & 68,8 & \\
\hline MDMA $(n=14)$ & 5 & 35,7 & 9 & 64,3 & \\
\hline$(n=15)$ & 5 & 33,3 & 10 & 66,7 & $>0,05$ \\
\hline Ketamin & 3 & 50,0 & 3 & 50,0 & כ0, \\
\hline$(n=72)$ & 31 & 43,1 & 41 & 56,9 & \\
\hline
\end{tabular}

Nhận xét: Bệnh nhân cần phải sử dụng thuốc an thần gặp ở tất cả các nhóm ma túy (Diazepam $28 \mathrm{BN}$ và Aminazin $3 \mathrm{BN}$ ). Bệnh nhân ngộ độc Amphetamin cần phải sử dụng thuốc an thần nhiều nhất $(61,9 \%)$, tiếp theo là ngộ độc nhóm Ketamin $(50,0 \%)$, MDMA $(35,7 \%)$; THC $(33,3 \%)$ và MET $(31,3 \%)$.

Bảng 4. Kêt quả điều trị

\begin{tabular}{|c|c|c|c|c|c|}
\hline \multirow[t]{2}{*}{ Loại ma túy Kết quả } & \multicolumn{2}{|c|}{ Khỏi } & \multicolumn{2}{|c|}{$\begin{array}{c}\text { Còn rối loạn tâm thân } \\
\text { sau điêê trị }\end{array}$} & \multirow[t]{2}{*}{ p } \\
\hline & $\mathbf{n}$ & $\%$ & $\mathbf{n}$ & $\%$ & \\
\hline Amphetamin $(n=21)$ & 19 & 90,5 & 2 & 9,5 & \multirow{6}{*}{$>0,05$} \\
\hline $\operatorname{MET}(n=16)$ & 16 & 100,0 & 0 & 0 & \\
\hline MDMA $(n=14)$ & 12 & 85,7 & 2 & 14,3 & \\
\hline THC $(n=15)$ & 14 & 93,3 & 1 & 6,7 & \\
\hline Ketamin $(n=6)$ & 5 & 83,3 & 1 & 16,7 & \\
\hline Tống $(n=72)$ & 66 & 91,7 & 6 & 8,3 & \\
\hline
\end{tabular}

Nhân xét: Có $66 \mathrm{BN}(91,7 \%)$ điều trị khỏi và còn rối loạn tâm thần sau điều trị là $6 \mathrm{BN}(8,3 \%)$. Tỉ lệ còn loạn thần cao nhất là bệnh nhân sử dụng Ketamin $(16,7 \%)$, tiếp đến là MDMA $(14,3 \%)$, Amphetamin (9,5\%), THC (6,7\%), không gặp ở bệnh nhân nào sử dụng MET.

\section{BÀN LUÂN}

4.1 Đặc điểm chung của nhóm nghiên cứu. Tuổi trung bình của các bệnh nhân nghiên cứu là 30,57 \pm 9,3 tuổi. Các loại ma túy trong nghiên cứu là loại ma túy mới gặp nhiêu trong thời gian gần đây, chủ yếu ở nhóm bệnh nhân trẻ. Bệnh nhân của chúng tôi chủ yếu là nam giới (72,2\%), nữ giới chỉ chiếm 27,8\%. Đặc điểm về giới này cũng phổ biến trong các nghiên cứu, nhiều tác giả nhận thấy số bệnh nhân nam sử dụng và ngộ độc ma túy cao hơn ở nũ. Tuy nhiên, có báo cáo cho thấy tỉ lê người nghiện là nữ giới đang có xu hướng tăng trong những năm gần đây [3].

4.2 Các biện pháp điêu trị. Hồi sức hô hấp, tim mạch và sử dụng thuốc giải độc đặc hiệu là các biện pháp điều trị cơ bản đối với ngộ độc chất gây nghiện. Trong thực tế, ngộ độc các chất ma túy mới, điều trị hổ trơ triệu chứng và biến chứng là chủ yếu. Trước kia ngộ độc opi có thuốc kháng độc đặc hiệu là Naloxon thì ngộ độc ma túy tổng hợp chưa có thuốc kháng độc đặc hiệu. Khai thông đường thở, thở oxy và thông khí nhân tạo là cần thiết đối với một số bệnh nhân. Những bệnh nhân kích thích, co giật, tiêu cơ vân, hôn mê, tăng thân nhiệt.... cần được 
điều trị hỗ trợ triệu chứng và các biến chứng.

Các bệnh nhần được trong nghiên cứu được chỉ định truyền dịch với mục đích đảm bảo khối lượng tuần hoàn, tăng cường bài niệu, tăng thải chất độc. Mặt khác các ma túy tổng hợp cũng thường có hội chứng cường giao cảm và serotonin gây tình trạng kích thích vật vã, run cơ, sốt... làm mất nước, tiêu cơ vân... nên truyền dịch và điện giải cũng hạn chế được các biến chứng cho bệnh nhân. Chúng tôi chỉ có 1 bệnh nhân sau sử dụng MET cần dùng thuốc vận mạch $(1,4 \%)$. Ở bệnh nhân ngộ độc, các hướng dẫn đưa ra đối với hồi sức bao gồm dùng vận mạch cho các bệnh nhân tự huyết áp, theo dõi sát tăng gánh thể tích, chú ý đánh giá lượng dịch vào và ra. Tổn thương tim mạch năng như suy tim, nhồi máu cơ tim có thể gặp ở những bệnh nhân ngộ độc ma túy tổng hợp nặng [4 ], tuy nhiên chúng tôi không gặp trong nghiên cứu này.

Bệnh nhân ngộ độc chất gây nghiện thường có rối loạn hô hấp, các can thiệp hỗ trợ hô hấp sớm rất cần thiết để hạn chế biến chứng và tử vong. Tỉ lệ bệnh nhân được thở oxy trong nghiên cứu là $19,4 \%$, tỉ lệ này cao nhất trong nhóm dùng Ketamin là $50,0 \%$ và thấp nhất là $12,5 \%$ trong nhóm dùng MET. Có 4 bệnh nhân cần thông khí nhân tạo $(5,6 \%)$, tỉ lệ cao nhất trong nhóm dùng ketamin $(16,7 \%)$, điều này phù hợp với tính chất dược lý của ketamine, vì ketamine cũng là một thuốc mê tĩnh mạch và được dùng trong y tế [5].

Một trong những biện pháp điều trị rất cơ bản và thường dùng khi cấp cứu các bệnh nhân ngộ độc ma túy tổng hợp là dùng thuốc an thần để điều trị tình trạng co giật, tăng trương lực cớ, kích thích vât vã [6]. Benzodiazepin có hiệu quá tốt trong điều trị chống co giật, ngoài ra các butyrophenon (Haloperidol và Droperidol) cũng được dùng. Trong nghiên cứu, có $43,1 \%$ số bệnh nhân trong nghiên cứu được chỉ định sử dụng thuốc an thần và hầu hết dùng Diazepam $(90,3 \%)$, số còn lại được dùng Aminazin $(9,7 \%)$. Những bệnh nhân ngộ độc Amphetamin cân phải dùng thuốc an thần nhiều nhất $(61,9 \%)$. Tỉ lệ này thấp hơn ở những nhóm sử dụng các loại thuốc khác: Ketamin $(50,0 \%)$, MDMA $(35,7 \%)$; THC $(33,3 \%)$ và MET $(31,3 \%)$. Chúng tôi không thây có sự khác biệt về tỉ lệ dùng thuốc an thần giữa các nhóm ma túy $(p>0,05)$. Các bệnh nhân phải sử dụng an thần gặp trong tất cả các loại ma túy, việc dùng thuốc an thần phụ thuộc mức độ ngộ độc và triệu chứng. Tuy nhiển, các triệu chứng như kích thích, bồn chồn, vật vã gặp nhiều trong nhóm bệnh nhân sử dụng
Amphetamin [4], đó cũng là lý do nhóm ma túy này phải sử dụng nhiều thuốc an thần hơn để kiểm soát tình trạng của bệnh nhân.

4.3 Kết quả điêuu trị: Kết quả nghiên cứu của chúng tôi cho thấy hầu hết bệnh nhân được điều trị khỏi hoàn toàn $(91,7 \%)$, còn rối loạn tâm thần sau điều trị là $8,3 \%$. Tỉ lệ còn loạn thần cao nhất là bệnh nhân sử dụng Ketamin $(16,7 \%)$, tiếp đến là MDMA $(14,3 \%)$, Amphetamin (9,5\%), THC (6,7\%), không gặp ở bệnh nhân nào sử dụng MET. Trên thực tế, quá liều Amphetamin có thể dẫn đến nhiều triệu chứng khác nhau, nhưng nếu được điêu trị thích hợp thì ít gây tử vong. Mức độ nặng của ngộ độc tăng theo liều lượng dùng và mức độ dung nạp của người dùng với chất gây ngộ độc. Ngộ độc Amphetamin gây tử vong thường liên quan đến co giật và hôn mê. Năm 2013, quá liều amphetamin, methamphetamin, và các dẫn chất khác dẫn đến khoảng gần bốn nghìn ca tử vong trên thế giới theo báo cáo tổng kết của Abubakar và cộng sự [7]. Trên thực tế, những bệnh nhân sử dụng ma túy kéo dài có thể gây rối loạn tâm thần ở các mức độ khác nhau, cần hỗ trợ của nhiều chuyên khoa để điều trị và cai nghiện cho bệnh nhân.

\section{KẾT LUÂ̂N}

Qua nghiên cứu 72 bệnh nhân, chúng tôi thấy các biện pháp điều trị chính cho bệnh nhân ngộ độc ma túy không phải nhóm opi là sự phối hợp các biện pháp hồi sức tích cực và điều trị triệu chứng: hồi sức tuần hoàn, sử dụng vận mạch $(1,4 \%)$, tăng cường bài niệu $(98,6 \%)$; hỗ trợ hô hấp 25\% (thở oxy 19,4\%; thở máy 5,6\%, gặp nhiều nhất ở nhóm ketamin); sử dụng an thần $43,1 \%$ (nhiều nhất ở nhóm amphetamin $61,9 \%$; dùng thuốc diazepam là 90,3\%). Kết quả điêu trị: khỏi $91,7 \%$, còn rối loạn tâm thần sau điêuu trị là $8,3 \%$.

\section{TÀI LIẸU THAM KHẢO}

1. Thủ tướng Chính phủ (2012). Chiến lược Quốc gia phòng, chống HIV/AIDS đến năm 2020 và tầm nhìn 2030 .

2. Nguyển Thị Dụ. Định hướng chung chẩn đoán và xữ trí ngộ độc cấp. Tư vấn chẩn đoán và xử trí nhanh ngộ độc câp. Nhà xuất bản Y học Hà Nội. 2004; 9-22.

3. Nicolas Rasmussen. Making the First AntiDepressant: Amphetamine in American Medicine, 1929-1950. Journal of the History of Medicine and Allied Sciences 2006, 61(3), 288-323.

4. White S. R. Amphetamine toxicity. Semin Respir Crit Care Med 2002 23(1), 27-36.

5. Robert J Hoffman. Ketamine poisoning. Uptodate 2020. 
6. Henry A Spiller, Hannah L Hays, Alfred Aleguas Jr. Overdose of drugs for attentiondeficit hyperactivity disorder: clinical presentation, mechanisms of toxicity, and management. CNS Drugs 2013, 27(7), 531-43.
7. Abubakar II., Tillmann T, Banerjee A et al. Global, regional, and national age-sex specific allcause and cause-specific mortality for 240 causes of death, 1990-2013: a systematic analysis for the Global Burden of Disease Study 2013. Lancet 2015 385(9963), 117-171.

\section{NGHIÊN CỨU YẾU TỐ LIÊN QUAN ĐẾN TỔN THƯƠNG VÕNG MAC HOÀNG ĐIỂM TRÊN LÂM SÀNG VÀ ĐÔ DÀY VÕNG MẠC HOÀNG ĐIỂM TRÊN OCT Ở MẮT CÂ̂N THỊ CAO}

\section{TÓM TẮT}

Mục tiêu: Tìm hiểu mối liên quan giữa tổn thương võng mạc hoàng điểm với chỉ số độ dày của vùng võng mạc hoàng điểm trên $\mathrm{OCT}$ ở mắt cân thị cao và tìm hiểu một số yếu tố nguy cơ. Đối tượng và phương pháp nghiên cứu: Nghiên cứu mổ tả cắt ngang trên 168 mắt của 88 bệnh nhân có mức độ cận thị $\leq-6,00 D$, tại khoa Khúc xạ - Bệnh viện Mắt Trung Ương. Kết quả: Tỷ lệ tổn thương võng mạc hoàng điểm $66,1 \%$; trong đó đáy mắt hình khảm 60,7\%; teo hắc võng mạc lan tỏa $4,2 \%$; teo hắc võng mạc dạng mảng $1,2 \%$. Độ dày võng mạc hoàng điểm trung bình là 244,93 $\pm 29,09 \mu \mathrm{m}$, mỏng nhất là $124 \mu \mathrm{m}$, dày nhất là $344 \mu \mathrm{m}$. Độ dày võng mạc vùng hoàng điểm trung tâm và vùng hoàng điểm trên các mắt có tổn thương mỏng hơn so với các mắt không có tổn thương đáy mắt, sự khác biệt có ý nghĩa thổng kê với $\mathrm{p}<0,05$. Các yếu tố nguy cơ có liên quan đến tổn thương võng mạc hoàng điểm: mức độ cận thị càng cao, trục nhãn cầu càng dài, thời gian mắc cận thị càng nhiều, tuổi bệnh nhân càng cao thì nguy cơ tổn thương đáy mắt càng nhiều. Mặc dù có sự mỏng đi của chiêu dày võng mạc vùng hoàng điểm trên các mắt cận thị cao nhưng nghiên cứu không phát hiện thấy mối liên quan giữa độ dày võng mạc vùng hoàng điểm trung bình và các yếu tố khác như tuổi, thời gian mắc cận thị, mức độ cận thị, chiều dài trực nhãn cầu. Kết luận: Chiều dày võ̃ng mạc hoàng điểm trên OCT mỏng hớn ở mắt có tổn thương võng mac hoàng điểm so với mắt không có tổn thương. Mức độ cận thị, chiều dài trực nhãn câu, tuổi và thời gian mắc cận thị là những yểu tố nguy cơ chính gây tổn thương võng mac hoàng điểm.

\section{SUMMARY}

STUDYING FACTORS RELATED TO THE MACULAR RETINAL CHANGES IN CLINIC AND THE MACULAR RETINAL THICKNESS BY OCT IN HIGH MYOPIC EYES

${ }^{1}$ BV Mắt trung ương

Chịu trách nhiệm chính: Nguyễn Thị Thu Hiền

Email: Thuhienvnio@gmail.com

Ngày nhận bài: 24.2.2021

Ngày phản biên khoa hoc: 5.4.2021

Ngày duyệt bài: 14.4 .2014
Nguyễn Thị Thu Hiền'1, Phạm Thị Minh Châu ${ }^{1}$

Objective: To find out the relationship between macular retinal changes with the macular retinal thickness by OCT in high myopia and some risk factors. Methods: A cross-sectional study on 168 eyes of 88 patients with high myopia was conducted between January 2020 and August 2020 at the Refraction Department of Vietnam National Institute of Ophthalmology. Data collected included history related to myopia progression and macular zone, macular thickness in OCT. Results: The maculopathy $66.1 \%$, tessellated fundus $60.7 \%$, diffuse choroiretinal atrophy $4.2 \%$, patchy choroiretinal atrophy $1.2 \%$. Macular thickness average was $244.93 \pm 29.09 \mu \mathrm{m}$, thinnest was $124 \mu \mathrm{m}$ and thicknest was $344 \mu \mathrm{m}$. Macular thickness in tessellated fundus, diffuse choroiretinal atrophy were thinner than patchy choroiretinal atrophy. The risk factors of myopiarelated retinal changes: high power of myopic, longer axial length, duration of myopia and age of patients related to myopic maculopathy. But no evidence of these risk factors related with macular thickness in OCT despite of thinner of macular thickness in high myopia patients. Conclusions: The thickness of macular retinal by OCT in the eyes with macular retinal changes is thinner. Myopic level, axial length, age and duration of myopia were the risk factors of myopia-related retinal changes.

\section{I. ĐĂT VẤN ĐỀ}

Cận thị, đặc biệt cận thị cao là tật khúc xạ phổ biến hiện nay, gây ảnh hưởng chủ yếu đến thị lực, làm suy giảm chất lượng cuộc sống đồng thời gây ra gánh nặng kinh tế đáng kể cho cá nhân và toàn xã hội. Theo Tổ chức y tế thế giới dự đoán đến năm 2050, tỷ lệ cận thị có thể đến $52 \%$ dân số thế giới (khoảng 5 tỷ người), trong đó cận thị cao chiếm $10 \%{ }^{1}$. Cận thị cao do sự kéo dài trục nhãn cầu và liên quan đến sư thay đổi cấu trúc của protein collagen, có thể dẩn đến những thay đổi thoái hóa và mỏng của võng mạc, hắc mạc và củng mạc. Với việc tích hợp các kỹ thuật mới như chụp cắt lớp võng mạc quang học OCT (optical coherence tomography) giúp hố trợ các bác sỹ nhãn khoa trong việc phát hiện, theo dõi và định hướng điều trị các tổn thương 